\title{
Modelling the impact of climate change on the atmospheric transport and the fate of persistent organic pollutants in the Arctic
}

\author{
K. M. Hansen ${ }^{1}$, J. H. Christensen ${ }^{1}$, C. Geels ${ }^{1}$, J. D. Silver ${ }^{1,2}$, and J. Brandt ${ }^{1}$ \\ ${ }^{1}$ Department of Environmental Science and Arctic Research Centre, Aarhus University, \\ Frederiksborgvej 399, 4000 Roskilde, Denmark \\ ${ }^{2}$ now at: School of Earth Sciences, University of Melbourne, Victoria, 3010, Australia \\ Correspondence to: K. M. Hansen (kmh@envs.au.dk)
}

Received: 8 January 2015 - Published in Atmos. Chem. Phys. Discuss.: 5 March 2015

Revised: 25 May 2015 - Accepted: 1 June 2015 - Published: 15 June 2015

\begin{abstract}
The Danish Eulerian Hemispheric Model (DEHM) was applied to investigate how projected climate changes will affect the atmospheric transport of 13 persistent organic pollutants (POPs) to the Arctic and their environmental fate within the Arctic. Three sets of simulations were performed, one with present day emissions and initial environmental concentrations from a 20-year spin-up simulation, one with present day emissions and with initial environmental concentrations set to zero and one without emissions but with initial environmental concentrations from the 20-year spin-up simulation. Each set of simulations consisted of two 10-year time slices representing the present (1990-2000) and future (2090-2100) climate conditions. DEHM was driven using meteorological input from the global circulation model, ECHAM/MPI-OM, simulating the SRES (Special Report on Emissions Scenarios) A1B climate scenario. Under the applied climate and emission scenarios, the total mass of all compounds was predicted to be up to $55 \%$ lower across the Northern Hemisphere at the end of the 2090s than in the 1990s. The mass of HCHs within the Arctic was predicted to be up to $38 \%$ higher, whereas the change in mass of the PCBs was predicted to range from $38 \%$ lower to $17 \%$ higher depending on the congener and the applied initial environmental concentrations. The results of this study also indicate that contaminants with no or a short emission history will be more rapidly transported to and build up in the arctic environment in a future warmer climate. The process that dominates the environmental behaviour of POPs in the Arctic under a future warmer climate scenario is the shift in mass of POPs from the surface media to the atmosphere induced by the higher mean temperature.
\end{abstract}

This is to some degree counteracted by higher degradation rates also following the higher mean temperature. The more dominant of these two processes depends on the physical-chemical properties of the compounds. Previous model studies have predicted that the effect of a changed climate on the transport of POPs to the Arctic is moderate relative to the effect of proposed changes in emissions, which is confirmed in this study. However, the model studies do not agree on whether climate change acts to reduce or increase environmental concentrations of POPs in the Arctic, and further work is needed to resolve this matter.

\section{Introduction}

The climate has changed in recent decades with the main sign being an increase in global mean temperature. In both the 4th and the recent 5th IPCC Assessment Report (AR4 and AR5), the multi-model ensembles project an increase in the global mean temperature in the range of $1-6^{\circ} \mathrm{C}$ by the end of the 21st century, relative to pre-industrial temperature levels (IPCC, 2007; Rogelj et al., 2012). The broad range in the projected temperature increase is linked to the various greenhouse gas emission scenarios used as input to the climate simulations.

Within the Arctic these changes are projected to be larger than elsewhere. According to one of the intermediate emission scenarios applied in AR4, the SRES (Special Report on Emissions Scenarios) A1B scenario, the average temperature increase in the Arctic exceeds $9{ }^{\circ} \mathrm{C}$ by the end of the $21 \mathrm{st}$ century compared to the 1990s (Hedegaard et al., 2012). The 
increasing temperature leads to enhanced seasonal melting of the Arctic Ocean sea ice, retreating of glaciers and melting of the Greenland ice sheet. Changes are also projected for precipitation patterns as well as in weather patterns in general.

Climate change impacts the physical and chemical processes in the atmosphere, including atmospheric transport pathways, chemical composition, air-surface exchange processes, natural emissions, etc., see Jacob and Winner (2009) for a review. Changes in climate alone might lead to both lower or higher levels of specific pollutants in the atmosphere leading to a lower or higher exposure, which can be referred to as a "climate benefit" or "climate penalty", respectively. During the last decade a number of studies have examined the effects of climate change on air pollutants such as ozone (Hedegaard et al., 2008, 2012; Anderson and Engardt, 2010; Langner et al., 2012) and particulate matter (Hedegaard et al., 2013; Colette et al., 2013; Simpson et al., 2014). So far, the most robust signal is seen for ozone with an overall climate penalty projected for the future; however, there are large uncertainties associated with, for example, the natural sources for ozone precursors and their sensitivity to climate changes (Langner et al., 2012). It has also been shown that this kind of study is very dependent on the applied climate input (Manders et al., 2012).

The environmental fate of persistent organic pollutants (POPs) is determined by many different environmental factors, several of which may be affected by climate change, thus making the combined effect difficult to predict. A report from a UNEP/AMAP expert group outlines qualitatively the effects of the warming of the climate on the cycling and fate of POPs in the environment (UNEP/AMAP, 2011): increasing temperatures can lead to changed partitioning between the different media as well as to enhanced revolatilization from historically deposited compounds, which can lead to larger atmospheric transport. Higher temperatures also increase degradation rates in both air and surface media. Melting of polar ice caps and glaciers will result in larger airsurface exchange and the melting ice may release stored POPs to the marine and atmospheric environments. Higher wind speed may lead to enhanced atmospheric transport downwind of major source areas and increasing precipitation in the Arctic may lead to increasing deposition.

The effect of a changed climate on the transport and fate of POPs in the Arctic has been investigated in a few studies with a range of different modelling approaches and model setups (Lamon et a., 2009; Armitage et al., 2011; Gouin et al., 2013; Wöhrnschimmel et al., 2013, Armitage and Wania, 2013). Despite differences in modelling approaches, the studies generally predict that the effect of changed climate on simulated environmental concentrations is within a factor of two. However, the applied models in the previous studies have a low spatial resolution with 10 zonally averaged climate zones and 4 atmospheric layers (Armitage et al., 2011; Armitage and Wania, 2013), 25 geographically explicit compartments (Gouin et al., 2013) or $15^{\circ} \times 15^{\circ}$ regular grid and
2 atmospheric layers (Lamon et al., 2009; Wöhrnschimmel et al., 2013) as well as simplified representations of important atmospheric processes. It is thus important to test whether the predictions from these studies are reliable using more advanced models.

The aim of this study is to investigate how a changed climate will affect the fate of POPs with special focus on the transport to and fate within the Arctic, and to determine if there will be a climate penalty or benefit on POPs in terms of higher or lower environmental concentrations and thus higher or lower potential exposure. The applied model has a much higher spatial resolution and with more detailed descriptions of atmospheric degradation and airborne particulate matter than previous model studies. The model was previously applied to study the effect of climate change on future atmospheric levels of ozone and particulate matter (Hedegaard et al., 2008, 2012, 2013; Langner et al., 2012; Simpson et al., 2014).

\section{Model}

We applied the Danish Eulerian Hemispheric Model (DEHM), a 3-D dynamic atmospheric chemistry-transport model covering the Northern Hemisphere with a horizontal resolution of $150 \mathrm{~km} \times 150 \mathrm{~km}$ and 20 vertical layers extending to a height of $10 \mathrm{hPa}$. DEHM comprises a comprehensive chemistry scheme including full ozone chemistry and particulate matter and is driven by meteorological data (temperature in air and surface media, pressure, wind velocity, humidity, solar radiation, cloud cover and sea ice cover) from a numerical weather prediction model. A detailed description of the model can be found in Christensen (1997), Frohn et al. (2002), and Brandt et al. (2012). DEHM has successfully been applied to study the transport and fate of a range of chemical compounds to the Arctic, including sulphur and sulphate (Christensen, 1997), mercury (Christensen et al., 2004; Skov et al., 2004), POPs (Hansen et al., 2004, 2008a, b), and Decamethylcyclopentasiloxane (Krogseth et al., 2013). Two-way air-surface gas exchange processes as well as intra-compartmental processes are included for the surface compartments soil, water, vegetation, and snow (Hansen et al., 2004, 2008a). Model evaluations against measured air concentrations show reasonable agreement with predicted concentrations for a range of persistent compounds (Hansen et al., 2004, 2006, 2008a, b; McLachlan et al., 2010; Genualdi et al., 2011; Krogseth et al., 2013).

Most of the environmental processes described in DEHM are climate-dependent and they will therefore affect the predicted fate of POPs under a changed climate. Temperature is the main driver that affects the partitioning between gas- and particle-phase POPs in air, degradation of gas-phase compounds in air, vegetation and snow, degradation in soil and water as well as the air-surface gas-exchange for the surface media. Changes in precipitation patterns will affect the scav- 
enging of POPs from the atmosphere and the flush-through of water of the soil compartment and changes in the snow cover and sea ice cover will affect the air-surface gas-exchange for the surface media (Hansen et al., 2004, 2008a). However, due to the complexity of the DEHM model it is difficult to separate the effect of the individual processes on the results.

\section{Model set-up}

A total of 13 different POPs are included in the model simulations: $\alpha-, \beta$-, and $\gamma-\mathrm{HCH}$ and $10 \mathrm{PCB}$ congeners: PCB8, PCB28, PCB31, PCB52, PCB101, PCB118, PCB138, PCB153, PCB180, and PCB194. In addition, the simulations are made with the regular chemistry scheme, including 67 compounds. This ensures a proper description of airborne particulate matter with which POPs can associate and the $\mathrm{OH}$ radicals, the primary degradation oxidant for POPs in the atmosphere.

We have performed three sets of simulations, one set with present day emissions and initial environmental concentrations from a 20-year spin-up simulation (the ES simulations), one set with present day emissions and with initial environmental concentrations set to zero (the E simulations), and one set without emissions but with initial environmental concentrations from the 20-year spin-up simulation (the "S" simulations). The spin-up simulation was initialized with zero environmental concentrations for all compounds except for $\alpha-\mathrm{HCH}$ in which case environmental concentrations were taken from a previous study using a 45-year spin-up period (see Table S1 in the Supplement). Each set of simulations consist of two 10-year time slices representing present (1990-2000, ES19, S19 or E19) and future (2090-2100, ES20, E20 or S20) climate. We have applied the same emissions to the atmosphere in the ES and E simulations (see Table S1 in the Supplement). With this set-up the difference in predicted concentrations for each set of simulations arises only from the effect the difference in climate input has on the transport and deposition processes. As driver of the simulations we have applied meteorological data obtained from a model simulation made with the ECHAM5/MPI-OM model (Roeckner et al., 2003, 2006; Marsland et al., 2003) simulating the SRES A1B scenario (Nakicenovic et al., 2000). The SRES A1B scenario projects the global average temperature to increase by $\sim 3^{\circ} \mathrm{C}$ by the end of the $21 \mathrm{st}$ century with large seasonal and regional differences in the warming with annual temperature increase exceeding $6{ }^{\circ} \mathrm{C}$ in the sub-polar regions of Asia, North America, and Europe. The average sea ice extent in the Arctic is estimated to retreat by approximately $40 \%$ and over the Barents Sea the sea ice is predicted to vanish completely by the end of the 21 st century. The globally averaged precipitation changes only slightly, although there are large regional and seasonal differences. The winter precipitation over the temperate and Arctic regions is projected to increase by $10-50 \%$. The global temperature change related to the SRES A1B scenario from AR4 is quite similar to the RCP6 scenario used in the IPCC AR5 (Rogelj et al., 2012). The SREAS A1B is only one of several climate change scenarios and represents an intermediate development of the climate. The projected changes in this study should be viewed in this context.

\section{Input data}

DEHM requires physical-chemical properties and emission data for each of the modelled compounds as input for the model simulations. Temperature-dependent physicalchemical properties for the HCHs are from Xiao et al. (2004) and for the PCBs from Schenker et al. (2005), degradation rates in air are derived from Beyer et al. (2003), and reaction half lives in soil and water are from common model input properties for the ArcRisk project (Wöhrnschimmel, personal communication, 2010; Table S2). $\alpha$-HCH emissions for the year 2000 are from Hansen et al. (2008a), $\beta$ - $\mathrm{HCH}$ emissions are calculated as $1 / 6$ of the $\alpha-\mathrm{HCH}$ emissions and $\gamma$-HCH are calculated emissions for the year 2005 (Li et al., 2008). For the PCBs, annual emissions from 2007 based on the high emission scenario from Breivik et al. (2007) are applied (Table S1)

\section{Results and discussion}

The simulations all apply input from one possible climate change scenario and this should therefore be considered as a sensitivity study of how the results from the DEHM model responds to the changed climate input in that particular scenario. We have calculated the total mass in the entire model domain and within the Arctic, defined as the area north of the Arctic Circle $\left(66.5^{\circ} \mathrm{N}\right)$ in this study, and compared the results of the two time slices for the three model scenarios. The largest differences are found for the least chlorinated PCB congeners $(55 \%)$ for the S scenario (Fig. 1). Plots of the monthly averaged total mass as well as masses in air, soil and water, the distribution between the different media, and the relative difference in total mass in the media within the entire model domain as well as within the Arctic region are included in the Supplement (Figs. S3-S10).

\subsection{Test of statistical significance}

A statistical test was applied to assess the significance of differences in the modelled masses of POPs in the different media between the 1990s and 2090s. We have calculated the difference of the annual averaged mass in air, water and soil and in total (Figs. S1 and S2 in the Supplement), fitted a linear trend and tested if the trend of the annual differences over the modelled decade is significant compared to the variability around the trend using a Student's $t$ test (Table S3). By evaluating the variability around the trend of the annual differ- 

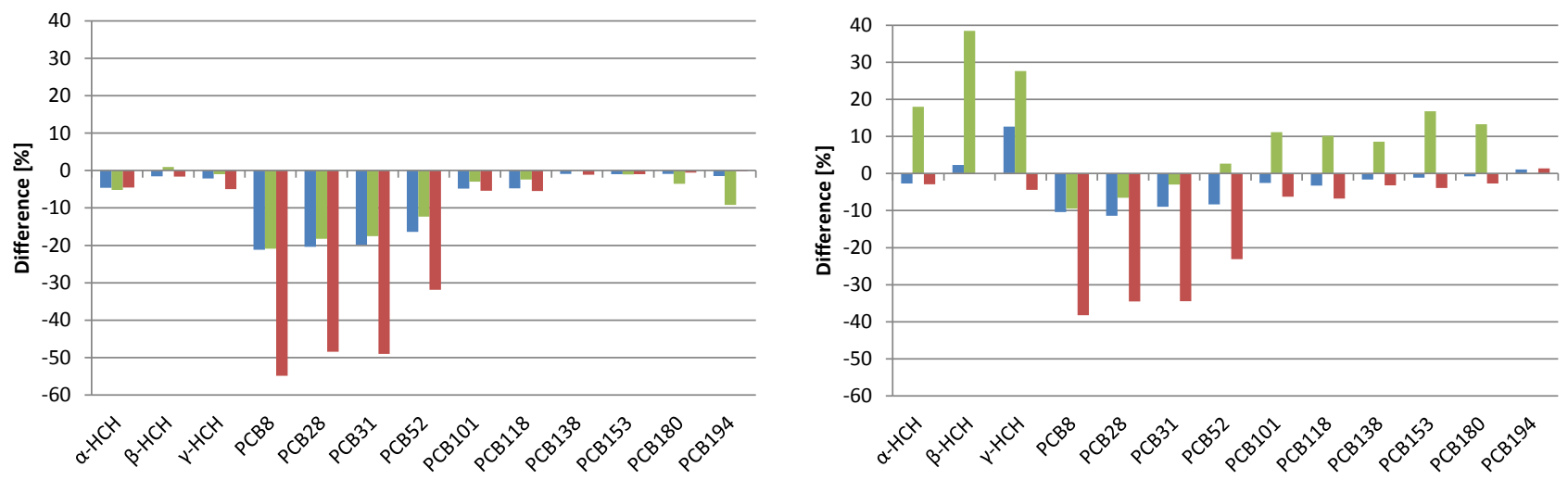

Figure 1. Difference in total mass between the 1990s and the 2090s calculated from the linear trend of the difference in annual averages compared to the average mass in 1999 in the entire model domain (left) and in the Arctic, defined as the area north of the Arctic Circle $\left(66.5^{\circ} \mathrm{N}\right)$ (right), for the ES scenario (blue), the E scenario (green) and the S scenario (red).

ences instead of the differences themselves we ensure that the data are independent which is an assumption needed for the $t$ test. The mass is building up in the model during the model simulations due to the emissions, but the same emissions are applied in both time slices, so the trend of the annual differences in mass is a good measure for the climate change impacts. Although there are uncertainties in the model associated with the process parameterizations and the input parameters, these are evened out when comparing two model simulations with the same model set-up. The differences in mass between the two time slices for the three simulations within the whole domain and within the Arctic are displayed in Table 1. Only differences with significance levels lower than 0.1 are shown.

The studied compounds behave differently depending on their physical-chemical properties and emission history in the simulations, and there are only a few general tendencies in the behaviour of them. For all three sets of simulations the total mass within the entire model domain is lower in the 2090 s than in the 1990s for all compounds except for $\beta$ - $\mathrm{HCH}$ for the $\mathrm{E}$ scenario (Fig. 1). The mass in soil and water are also lower in the 2090s than in the 1990s for most compounds with a few exceptions. The differences in air are only statistical significant for a few compounds. For the Arctic there are more exceptions from these general tendencies (Table 1).

\section{$3.2 \alpha-\mathrm{HCH}$}

The mass of $\alpha-\mathrm{HCH}$ in soil and ocean water within the entire model domain is lower in the 2090s than in the 1990s, but the mass in air is higher in the 2090s for all three sets of simulations (Fig. S4). Highest air concentrations are seen over the countries and regions with most recent use, such as India, Southeast Asia, Tunisia and Nigeria at the end of the 1990s (Fig. 2). High concentrations are also seen over the Pacific and the North Atlantic oceans with sharp land-sea contrasts, which show that revolatilization from the oceans is a ma- jor source of atmospheric $\alpha-\mathrm{HCH}$ in these areas. The pattern is similar at the end of the 2090s but with generally higher concentrations in the entire model domain. Largest relative differences between the two periods are found over the Arctic and North America (Fig. 2). The large relative differences over Africa and the Pacific Ocean at the border of the domain are not considered here because the concentrations are very low in these areas.

The averaged ocean water concentration in the Arctic is lower in 2099 than in 1999 (Fig. 2). There are regional differences with lower concentrations around Svalbard, in the eastern Arctic Ocean and in the Canadian Archipelago and higher concentrations in the central Arctic Ocean that are connected to the changes in sea ice cover in the Arctic. The average soil concentration within the Arctic is lower in the 2090s than in the 1990s, although large regional differences are seen for the soil compartment (Fig. 2).

Within the entire model domain around $90 \%$ of $\alpha-\mathrm{HCH}$ is found in water for all three scenarios (Fig. S5). Within the Arctic, higher fractions of $\mathrm{HCHs}$ are found in soil than in the entire model domain for all three scenarios, but water is still the predominant medium for the HCHs in the Arctic (Fig. S9). The total mass of $\alpha-\mathrm{HCH}$ within the Arctic decreases over the modelled decades for the ES and S simulations and the mass is lower at the end of the 2090s than the 1990s (Fig. S7). For the E simulations the total mass within the Arctic increases, but contrary to the whole model domain the mass within the Arctic is higher at the end of the 2090s than in the 1990s.

The overall response of $\alpha-\mathrm{HCH}$ to climate change is mainly driven by two processes, both of which are affected by the higher mean temperature in the 2090s than in the 1990s. Revolatilization from the surface is higher in the 2090s indicated by more mass in air and less in the surface media, and environmental degradation (dominated by degradation in air) is higher, indicated by the lower total mass in 
Table 1. Differences in mass between the two time slices for the three simulations within the whole domain and within the Arctic in total ( $T$ ), in air $(A)$, in water $(W)$, and in soil $(S) . \downarrow$ displays lower mass in the 2090s than in the 1990s and $\uparrow$ displays higher mass in the 2090s than in the 1990s. Only differences with significance levels lower than 0.1 are shown. The background colours display the statistical significance, red displays significance levels lower than 0.001 , orange displays significance levels lower than 0.01 , and yellow displays significance levels lower than 0.1 .

\begin{tabular}{|c|c|c|c|c|c|c|c|c|c|c|c|c|c|c|c|c|c|c|c|c|c|c|c|c|}
\hline & \multicolumn{8}{|c|}{ Emissions and spin-up - 'ES' } & \multicolumn{8}{|c|}{ Emissions only - 'E' } & \multicolumn{8}{|c|}{ Spin-up only - 'S' } \\
\hline & \multicolumn{4}{|c|}{ Whole domain } & \multicolumn{4}{|c|}{ Arctic } & \multicolumn{4}{|c|}{ Whole domain } & \multicolumn{4}{|c|}{ Arctic } & \multicolumn{4}{|c|}{ Whole domain } & \multicolumn{4}{|c|}{ Arctic } \\
\hline & $\mathbf{T}$ & A & $\mathbf{W}$ & $\mathbf{S}$ & $\mathbf{T}$ & A & $\mathbf{W}$ & $\mathbf{S}$ & $\mathbf{T}$ & A & $\mathbf{W}$ & $\mathbf{S}$ & $\mathbf{T}$ & A & $\mathbf{W}$ & $\mathbf{S}$ & $\mathbf{T}$ & A & $\mathbf{W}$ & $\mathbf{S}$ & $\mathbf{T}$ & A & W & $S$ \\
\hline$\alpha-\mathrm{HCH}$ & $\downarrow$ & $\uparrow$ & $\downarrow$ & $\downarrow$ & $\downarrow$ & $\uparrow$ & $\downarrow$ & $\downarrow$ & $\downarrow$ & $\uparrow$ & $\downarrow$ & $\downarrow$ & $\uparrow$ & & $\uparrow$ & $\downarrow$ & $\downarrow$ & $\uparrow$ & $\downarrow$ & $\downarrow$ & $\downarrow$ & $\uparrow$ & $\downarrow$ & $\downarrow$ \\
\hline$\beta-\mathrm{HCH}$ & $\downarrow$ & & $\downarrow$ & & $\uparrow$ & & $\uparrow$ & $\downarrow$ & $\uparrow$ & & $\uparrow$ & $\downarrow$ & $\uparrow$ & & $\uparrow$ & & $\downarrow$ & & $\downarrow$ & & $\uparrow$ & & $\uparrow$ & $\downarrow$ \\
\hline$V-\mathrm{HCH}$ & & & $\uparrow$ & $\downarrow$ & $\uparrow$ & & $\uparrow$ & $\downarrow$ & & & $\uparrow$ & $\downarrow$ & $\uparrow$ & & $\uparrow$ & $\uparrow$ & $\downarrow$ & $\uparrow$ & $\downarrow$ & $\downarrow$ & $\downarrow$ & $\downarrow$ & $\uparrow$ & $\downarrow$ \\
\hline PCB 8 & $\downarrow$ & & $\downarrow$ & $\downarrow$ & $\downarrow$ & & $\downarrow$ & $\downarrow$ & $\downarrow$ & & $\downarrow$ & $\downarrow$ & $\downarrow$ & & $\downarrow$ & $\downarrow$ & $\downarrow$ & & $\downarrow$ & $\downarrow$ & $\downarrow$ & & $\downarrow$ & \\
\hline PCB 28 & $\downarrow$ & & $\downarrow$ & $\downarrow$ & $\downarrow$ & & $\downarrow$ & $\downarrow$ & $\downarrow$ & & $\downarrow$ & $\downarrow$ & $\downarrow$ & & $\downarrow$ & & & & $\downarrow$ & & $\downarrow$ & & $\downarrow$ & $\downarrow$ \\
\hline PCB 31 & $\downarrow$ & & & $\downarrow$ & $\downarrow$ & & & $\downarrow$ & $\downarrow$ & & $\downarrow$ & $\downarrow$ & $\downarrow$ & & $\downarrow$ & & & & $\downarrow$ & & $\downarrow$ & & $\downarrow$ & $\downarrow$ \\
\hline PCB 52 & $\downarrow$ & & & $\downarrow$ & $\downarrow$ & & $\downarrow$ & $\downarrow$ & $\downarrow$ & & $\downarrow$ & $\downarrow$ & & & $\downarrow$ & $\uparrow$ & $\downarrow$ & & $\downarrow$ & $\downarrow$ & $\downarrow$ & & $\downarrow$ & $\downarrow$ \\
\hline PCB 101 & $\downarrow$ & & $\downarrow$ & $\downarrow$ & $\downarrow$ & & $\downarrow$ & $\uparrow$ & $\downarrow$ & & $\downarrow$ & $\downarrow$ & $\uparrow$ & & $\downarrow$ & $\uparrow$ & $\downarrow$ & $\downarrow$ & $\downarrow$ & $\downarrow$ & $\downarrow$ & $\downarrow$ & & $\downarrow$ \\
\hline PCB 118 & $\downarrow$ & & $\downarrow$ & $\downarrow$ & $\downarrow$ & & $\downarrow$ & $\uparrow$ & $\downarrow$ & & $\downarrow$ & $\downarrow$ & $\uparrow$ & & $\downarrow$ & $\uparrow$ & $\downarrow$ & $\downarrow$ & & $\downarrow$ & $\downarrow$ & $\downarrow$ & & $\downarrow$ \\
\hline PCB 138 & $\downarrow$ & & $\downarrow$ & $\downarrow$ & & & & $\uparrow$ & $\downarrow$ & & $\downarrow$ & $\uparrow$ & $\uparrow$ & & $\downarrow$ & $\uparrow$ & $\downarrow$ & $\downarrow$ & & $\downarrow$ & & $\downarrow$ & & $\downarrow$ \\
\hline PCB 153 & $\downarrow$ & & $\downarrow$ & $\downarrow$ & $\downarrow$ & & $\downarrow$ & $\uparrow$ & $\downarrow$ & & $\downarrow$ & $\uparrow$ & $\uparrow$ & & $\downarrow$ & $\uparrow$ & $\downarrow$ & $\downarrow$ & & $\downarrow$ & $\downarrow$ & $\downarrow$ & & \\
\hline PCB 180 & $\downarrow$ & $\downarrow$ & $\downarrow$ & $\downarrow$ & $\downarrow$ & $\downarrow$ & $\downarrow$ & $\uparrow$ & $\downarrow$ & $\downarrow$ & $\downarrow$ & $\downarrow$ & $\uparrow$ & & $\downarrow$ & $\uparrow$ & $\downarrow$ & $\downarrow$ & $\downarrow$ & $\downarrow$ & $\downarrow$ & $\uparrow$ & $\downarrow$ & 个 \\
\hline PCB 194 & $\downarrow$ & $\downarrow$ & $\downarrow$ & $\downarrow$ & $\uparrow$ & $\downarrow$ & $\downarrow$ & $\uparrow$ & $\downarrow$ & $\downarrow$ & $\downarrow$ & $\downarrow$ & & $\downarrow$ & $\downarrow$ & $\uparrow$ & $\downarrow$ & $\downarrow$ & $\downarrow$ & $\uparrow$ & $\uparrow$ & $\uparrow$ & $\downarrow$ & $\uparrow$ \\
\hline
\end{tabular}

the model domain in the 2090s than in the 1990s for all scenarios.

The higher concentrations in the air lead to a larger atmospheric transport of $\alpha-\mathrm{HCH}$ to the Arctic. Larger atmospheric transport can also arise from changes in wind patterns, but this cannot be quantified from these simulations. For the ES and $\mathrm{S}$ simulations the larger degradation counteracts the increased transport, leading to lower overall mass in the Arctic in the 2090s than in the 1990s. For the E simulations the larger atmospheric transport to the Arctic leads to rapid deposition to the relatively clean surface compartments, where the degradation is lower than in the atmosphere. Climateinduced changes in the surface characteristics with less sea ice and snow cover enhances the possible transfer to soil and ocean water, both of which are surface media with more accumulation potential due to the lower degradation rates. The effect of this process is larger than the effect of the higher degradation rates, and the result is thus more mass in the Arctic in the 2090s than in the 1990s for the E simulation. The differences in mass of $\alpha-\mathrm{HCH}$ are all statistically significant within a 0.1 significance level except for air in the Arctic for the E simulation.

\section{$3.3 \quad \beta-H C H$}

Water is also the dominant medium for $\beta-\mathrm{HCH}$ as it is for $\alpha$-HCH (Figs. S5 and S9), but $\beta$-HCH has a generally different behaviour in the environment compared with $\alpha$-HCH. It has a lower $\log K_{\mathrm{AW}}$ and it is therefore more readily transferred to the oceans via wet and dry deposition (Li et al., 2002). It has a statistically significant higher overall mass in the 2090s than in the 1990s for the E simulation (Table 1). The mass within the Arctic is also statistically significantly higher in the 2090s than in the 1990s for all three scenarios, with the highest positive difference of all the compounds (38\%) for the E scenario (Fig. 1). This is due to the statistically significant higher mass in water (Table 1), which most probably arises due to a larger volatilization to air from soil combined with changes in the precipitation patterns that can lead to a more rapid transfer of $\beta-\mathrm{HCH}$ to the oceans close to the source areas.

The fraction found in the Arctic in this study is very low for all three scenarios (Fig. 3). The reason for this is that $\beta$ $\mathrm{HCH}$ is primarily transported to the Arctic via ocean currents (Li et al., 2002). This process takes several decades and is therefore not adequately represented in the 10-year model simulations in this study. The spatial distribution of $\beta-\mathrm{HCH}$ in this study is thus not representative for the distribution of $\beta-\mathrm{HCH}$ in the environment.

\section{$3.4 \gamma-\mathrm{HCH}$}

$\gamma-\mathrm{HCH}$ is the compound that displays the most mixed picture in terms of influence of climate change on the predicted mass in the three scenarios. The difference in total mass in the entire domain is negative but it is only statistically significant for the $\mathrm{S}$ scenario, whereas the total mass within the Arctic is higher in the 2090s than in the 1990s with a high statistical significance for the ES and the E scenarios, but not for the $\mathrm{S}$ scenario. As for the other $\mathrm{HCHs}$, water is the dominant medium for $\gamma$-HCH (Figs. S5 and S9). In contrast with $\alpha-\mathrm{HCH}$, the mass of $\gamma-\mathrm{HCH}$ increases during the mod- 


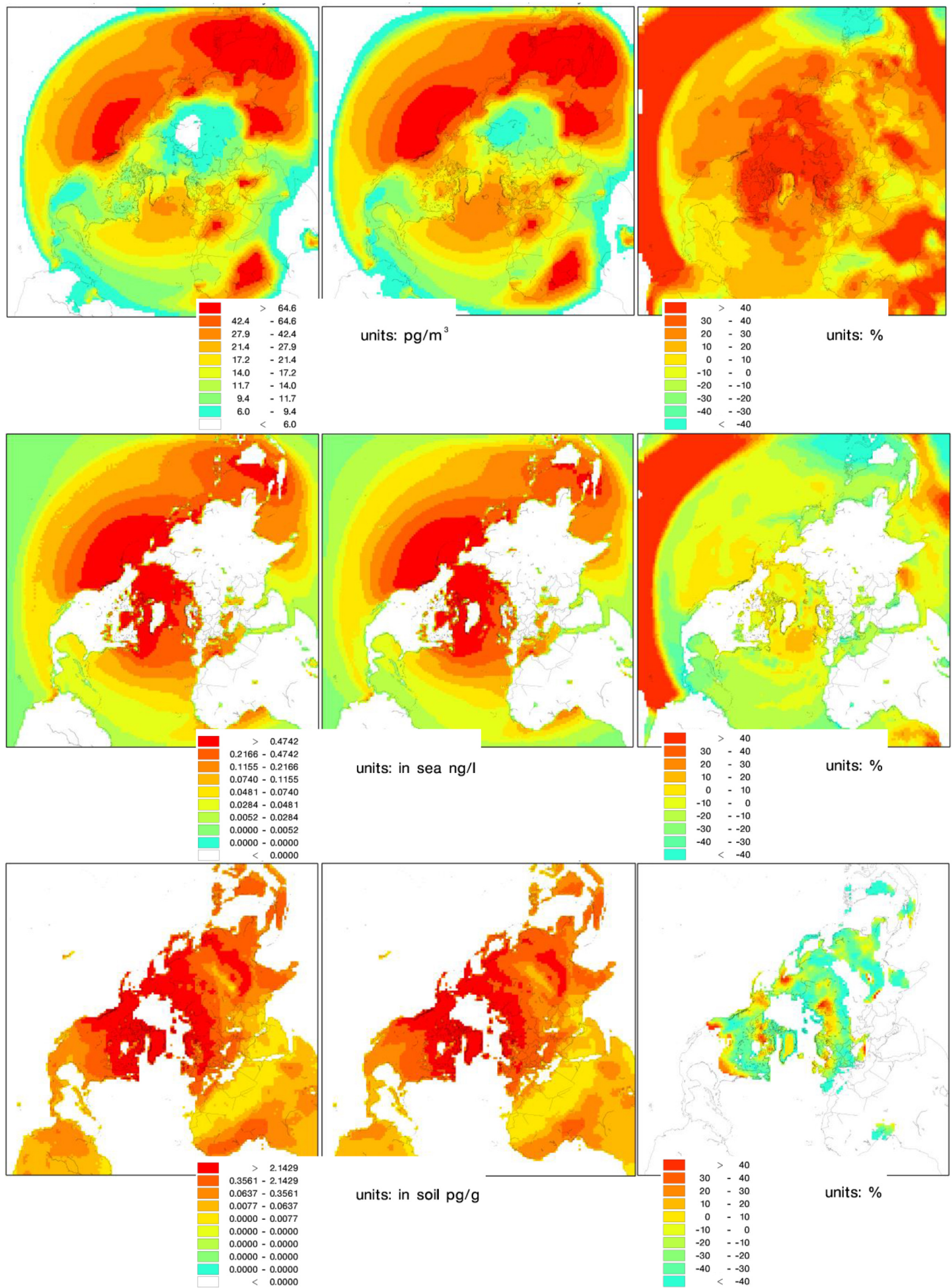

Figure 2. Annually averaged $\alpha-\mathrm{HCH}$ concentrations in the lowermost atmospheric layer (top row) in ocean water (middle row) and soil (bottom row) for 1999 (left column) and 2099 (middle column) and the difference in percent between 1999 and 2099 (right column) for the ES simulations. 


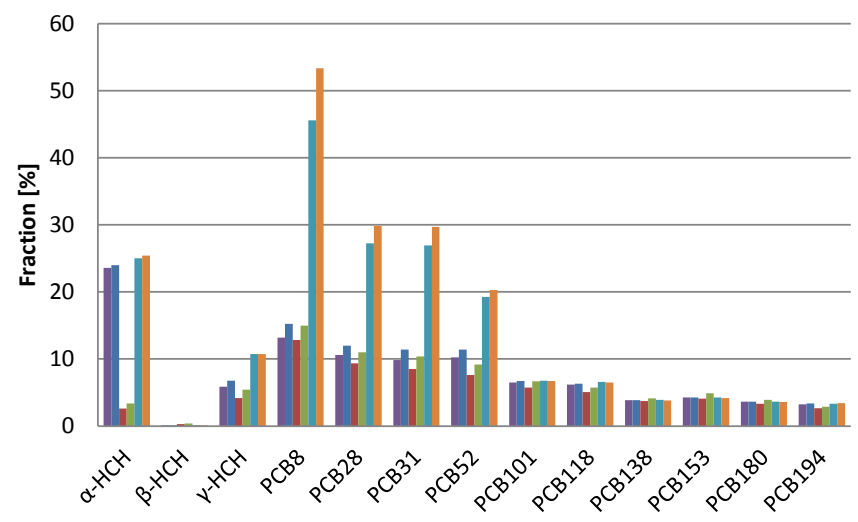

Figure 3. The fraction of the compounds found within the Arctic relative to the mass in the entire model domain calculated from the annual averages in the last simulated year for ES19 (purple), E19 (red), S19 (turquoise), ES20 (blue) E20 (green), and S20 (orange).

elled decades for the ES and S scenarios that both include emissions. The reason for this is that with the relatively short spin-up simulation, combined with a relatively high emission scenario, the concentrations are still building up in the modelled environment. Although the environmental degradation is larger in the 2090s than in the 1990s, the addition of fresh $\gamma-\mathrm{HCH}$ emissions to the model domain dominates and the differences between the 2 decades do not become statistically significant.

The total mass in the Arctic for the ES simulations is almost constant over the 1990s, whereas it increases in the 2090s (Fig. S7). The reason for this is that while the mass in soil increases in both simulations the mass in sea water decreases in the 1990s, whereas it increases in the 2090s (Fig. S8). This can be a result of a larger deposition to the sea in 2090s due to larger atmospheric transport to the Arctic and a larger sea surface available for deposition following the retreat of sea ice. The masses of $\gamma-\mathrm{HCH}$ in air are very similar for the ES and the E simulations (Figs. S4 and S8).

\section{PCBs}

The physical-chemical properties of the PCB congeners span a range of four orders of magnitude in $\log K_{\mathrm{OA}}(7-12)$ and almost one order of magnitude in $\log K_{\mathrm{AW}}(-2$ to -3 ) from the least chlorinated PCB8 to the most chlorinated PCB194. With higher $\log K_{\mathrm{OA}}$ values partitioning to particles in the air becomes an important process affecting the environmental fate of PCBs and thus the effect of climate change on the fate, in addition to the two processes dominating the fate of the HCHs. Particle- and gas-phase compounds are transported differently in the atmosphere; their deposition patterns are different, and most importantly particle-phase compounds are less degradable, with zero degradation assumed in the DEHM model (Hansen et al., 2008a). A higher temperature shifts the gas-particle equilibrium towards the gas phase in the air. Higher $\log K_{\mathrm{OA}}$ values also favours partitioning to organic phases in the surface media such as soil, where all the PCBs are predominantly found in the model (Fig. S5).

The total mass within the entire domain is lower in the 2090s than in the 1990s for all three scenarios, with the largest differences for the four least chlorinated congeners (PCB8-PCB52), which are primarily found in gas-phase in the atmosphere (Fig. 1). The effect of climate change on the fate of these congeners is dominated by the higher degradation resulting in up to $55 \%$ less mass within the model domain in the 2090s than in the 1990s. The total mass of these congeners is almost equal at the end of the ES19 and the E19 simulations and similarly for the ES20 and the E20 simulations. This indicates that the model relatively quickly reaches an overall steady-state between concentrations in air and in the surface compartments due to the relatively high environmental degradation rates for these congeners. The steady-state is not the same for the 2 decades, with the overall steady-state being lower for the 2090s than for the 1990s. This is due to the larger environmental degradation following the higher average temperature in the 2090s.

Degradation also dominates the fate of the intermediately chlorinated congeners (PCB101-PCB118) although not to the same extent as for the least chlorinated PCB congeners. The result is a relatively low, but still statistically significant, overall effect of climate change of less than $5 \%$ lower mass in the 2090s.

For the most chlorinated congeners (PCB138 and higher) the overall steady state is not reached at the start of the ES simulations, indicated by increasing environmental mass through the modelled decades (Fig. S3). The effect of climate change is even smaller for these congeners, but still statistically significant.

The effect of climate change on the total mass in the Arctic is smaller than the effect in the entire model domain, with a maximum of $38 \%$ difference for the least chlorinated congeners. This indicates that more mass is transported to the Arctic in the 2090s than in the 1990s. For the least chlorinated congeners (PCB8-PCB52) the result is a lower mass in the 2090s than in the 1990s due to the enhanced degradation. With increasing chlorination, the partitioning to particles is higher and the transport via the (non-degradable) particlephase thus leads to a smaller effect of the changed climate on atmospheric transport of the PCB congeners to the Arctic. Differences between the congeners (e.g. larger difference in mass of PCB153 than of PCB180 in the Arctic for the E simulation) can be due to the different emission patterns for the individual congeners.

The overall average mass in air in the entire model domain cannot be distinguished from each other at the end of the simulated decades except for the most chlorinated congeners (PCB153 and higher) regardless of the initial environmental concentrations and, to a lesser degree, the climate input (Fig. S4). This indicates that the dynamics of atmospheric 
concentrations of PCBs are dominated by primary emissions and that re-emissions from surfaces do not contribute considerably to the large-scale atmospheric transport and fate of PCBs.

The differences in total mass within the Arctic is in general more positive for the E scenario than for the ES scenario. For the light PCB congeners where the difference is most negative for the ES scenario, the differences for the $\mathrm{E}$ scenario are smaller. For the compounds with small negative difference for the ES simulation the difference for the E simulations are positive. For the studied compounds where the model predicts higher mass in the Arctic in the 2090s for the ES simulation, the difference in mass is larger for the E simulation, except for PCB194 (Fig. 1). This indicates that climate change acts to enhance atmospheric transport and subsequent accumulation in the Arctic for new contaminants to a larger degree than for compounds with longer emission histories. One possible explanation for the exception of PCB194 may be that there is a larger accumulation in soils in the 2090s. This will lead to a build-up of mass in the soil, but also to a larger loss from the soil compartment via run-through of excess water in the model. However, this needs to be investigated in further detail.

\subsection{Fraction of mass found in the Arctic}

We also examined the fraction of the total mass in the model domain that is found within the Arctic at the end of each of the simulations (Fig. 3). The fraction of the PCBs found within the Arctic is between 3 and $53 \%$ with largest fractions for the least chlorinated congeners and the highest overall for PCB8 in the S20 simulation. The highest fraction of the HCH's (25\%) is found for $\alpha-\mathrm{HCH}$ for the S20 simulation. The fraction found in the Arctic is higher in the 2090s than in the 1990s for all compounds and for all three scenarios. In general the differences between the scenarios are very small apart from the HCHs and the least chlorinated PCB congeners (PCB8-PCB52), where the fraction found in the Arctic is higher for the ES and the S simulations than for the E simulations. For $\alpha-\mathrm{HCH}$ the reason for this difference is that the initial environmental concentrations reflect 45 years of previous accumulation in contrast to the 20 years for the other compounds. For the least chlorinated PCB congeners the rapid degradation removes the compounds more slowly from the cold arctic environment than from the rest of the model domain and the concentrations in the $\mathrm{S}$ simulations are not sustained with fresh emissions as they are in the ES and $\mathrm{E}$ simulations.

\subsection{Comparison with previous results}

Armitage et al. (2011) and Gouin et al. (2013) recently reviewed the few model studies that have investigated the effect of a changed climate on the transport and fate of POPs in the Arctic. Lamon et al. (2009) applied a global grid- ded multimedia model to calculate steady-state solutions for PCB28 and PCB153 under the SRES-A2 climate scenario. A global geographically explicit multimedia model was applied to calculate steady state solutions for a range of hypothetical chemicals under the SRES-A1B scenario by Gouin et al. (2013). Wöhrnschimmel et al. (2013) applied a global gridded multimedia model forced with the SRES-A2 climate scenario and with average climate input for the period 19802000 to predict the effect of climate change on the transport of $\alpha-\mathrm{HCH}$ and PCB153 to the Arctic. A zonally averaged multimedia model was applied by Armitage and Wania (2013) to study the impact of changed climate conditions on the fate of a range of hypothetical chemicals forced with a climate change scenario resembling the SRES-A1B scenario.

The previous studies all apply models with different spatial resolution, different process parameterizations and input parameters as well as different climate change scenarios so a direct comparison of the results from this study with the previous model studies is therefore difficult. One common result is that the impact of climate change is moderate, with all studies but one predicting an effect of climate change on environmental concentrations of POPs within a factor of 2 . The differences projected in this study are in the lower end compared to previous predictions.

While the different models in general agree on the moderate effect of climate change on the environmental concentrations of POPs in the Arctic, they do not always agree on the sign of the changes. Although there is some disagreement between the previous model studies most of them predict higher air concentrations and lower ocean water concentrations of PCB153 in the Arctic. The results in this study are opposite to most of the previous studies but the predicted differences are not statistically significant. Apart from one of the previous model studies, all of the studies including $\alpha-\mathrm{HCH}$ predict higher air concentrations and lower ocean water concentrations in the Arctic. The results in this study are in accordance with the previous findings and they are statistically significant. Due to the complexity of the models it is not possible to determine the processes that are responsible for differences between the model predictions.

\section{Conclusions}

We have studied the effect of climate change on the fate of a range of POPs. Under the applied climate and emission scenarios, the total mass of all compounds was predicted to be lower by up to $55 \%$ across the Northern Hemisphere in a future warmer climate under the SRES A1B scenario. The mass of HCHs within the Arctic was predicted to be higher by up to $38 \%$, whereas the change in mass of the PCBs was predicted to range from $38 \%$ lower to $17 \%$ higher mass depending on the congener and the applied initial environmental concentrations. These differences are statistically significant for the HCHs, while not all of the results for the PCBs 
are statistically significant. It is not possible to state whether there is, in general, a climate penalty or a climate benefit on the transport of POPs into the Arctic in terms of higher or lower environmental concentrations and thus higher or lower potential exposure since it depends on the physical-chemical properties of the compounds as well as the initial environmental concentrations. The results of this study also indicate that contaminants with no or a short emission history will be more rapidly transported to and build up in the arctic environment in a future warmer climate.

From this study we have gained insight into how climate change affects the transport of a range of POPs to the Arctic and which processes are dominating the environmental behaviour of POPs in the Arctic in a future warmer climate scenario. The most dominating process is the shift in mass of POPs from the surface media to the atmosphere induced by the higher mean temperature. This is to some degree counteracted by higher degradation rates also following the higher mean temperature. The more dominant of these two processes depends on the physical-chemical properties of the compounds.

The results in this study confirm findings from previous studies using less complex models that the effect of a changed climate on the transport of POPs to the Arctic is moderate. Larger differences in environmental concentrations are predicted due to changes in emissions than due to changes in climate parameters (Lamon et al., 2009; Wöhrnschimmel et al., 2013). While the different models in general agree on the moderate effect of climate change on the environmental concentrations of POPs in the Arctic, they do not always agree on the sign of the changes, i.e. whether there is a climate penalty or a climate benefit on the environmental fate of POPs. This is due to differences in process parameterizations and in the physical-chemical parameters, emissions scenarios and climate change scenarios applied as input data. To identify which parameters and processes are creating the discrepancies between the models, a thorough model comparison such as the one conducted by Hansen et al. (2006) is needed.

\section{The Supplement related to this article is available online at doi:10.5194/acp-15-6549-2015-supplement.}

Acknowledgements. We gratefully acknowledge the contributions of Arctic Research Centre (ARC), Aarhus University. The research leading to these results has received funding from the European Community's Seventh Framework Programme FP7/2007-2013 - Environment (including Climate Change) FP7-2008-1 under Grant Agreement no 226534-ArcRisk, as well as from the Danish Environmental Protection Agency as part of the environmental support program Dancea - Danish Cooperation for Environment in the Arctic. The authors are solely responsible for all results and conclusions presented in the paper; these do not necessarily reflect the position of the Danish Environmental Protection Agency. This work is a contribution to the Arctic Science Partnership (ASP).

Edited by: S. Galmarini

\section{References}

Andersson, C. and Engardt, M.: European ozone in a future climate: Importance of changes in dry deposition and isoprene emissions. J. Geophys. Res., 115, D02303, doi:10.1029/2008JD011690, 2010.

Armitage, J. M. and Wania, F.: Exploring the potential influence of climate change and particulate organic carbon scenarios on the fate of neutral organic contaminants in the Arctic environment, Environ. Sci. Processes Impacts, 15, 2263-2272, 2013.

Armitage, J. M., Quinn, C. L., and Wania, F.: Global climate change and contaminants - An overview of opportunities and priorities for modelling the potential implications for long-term human exposure to organic compounds in the Arctic, J. Environ. Monit., 13, 1532-1546, 2011

Beyer, A., Wania, F., Gouin, T., Mackay, D., and Matthies, M.: Temperature dependence of the characteristic travel distance, Environ. Sci. Technol., 37, 766-771, 2003.

Brandt, J., Silver, J. D., Frohn, L. M., Geels, C., Gross, A., Hansen, A. B., Hansen, K. M., Hedegaard, G. B., Skjøth, C. A., Villadsen, H., Zare, A., and Christensen, J. H.: An integrated model study for Europe and North America using the Danish Eulerian Hemispheric Model with focus on intercontinental transport, Atmos. Environ., 53, 156-176, 2012.

Breivik, K., Sweetman, A., Pacyna, J. M., and Jones, K. C.: Towards a global historical emission inventory for selected PCB congeners - A mass balance approach 3. An update, Sci. Total Environ., 377, 296-307, 2007.

Christensen, J. H.: The Danish Eulerian hemispheric model - A three-dimensional air pollution model used for the Arctic, Atmos. Environ., 31, 4169-4191, 1997.

Christensen, J. H., Brandt, J., Frohn, L. M., and Skov, H.: Modelling of Mercury in the Arctic with the Danish Eulerian Hemispheric Model, Atmos. Chem. Phys., 4, 2251-2257, doi:10.5194/acp-42251-2004, 2004.

Colette, A., Bessagnet, B., Vautard, R., Szopa, S., Rao, S., Schucht, S., Klimont, Z., Menut, L., Clain, G., Meleux, F., Curci, G., and Rouil, L.: European atmosphere in 2050, a regional air quality and climate perspective under CMIP5 scenarios, Atmos. Chem. Phys., 13, 7451-7471, doi:10.5194/acp-13-7451-2013, 2013.

Frohn, L. M., Christensen, J. H., and Brandt, J.: Development of a high resolution nested air pollution model - the numerical approach, J. Comput. Phys., 179, 68-94, 2002.

Genualdi, S., Harner, T., Cheng, Y., MacLeod, M., Hansen, K. M., van Egmond, R., Shoeib, M., and Lee, S. C.: Global Distribution of Linear and Cyclic Volatile Methyl Siloxanes in Air, Environ. Sci. Technol., 45, 3349-3354, 2011.

Gouin, T., Armitage, J., Cousins, I., Muir, D., Ng, C. A., Reid, L., and Tao, S.: Influence of global climate change on chemical fate and bioaccumulation: The role of multimedia models, Environ. Toxicol. Chem., 32, 20-31, 2013. 
Hansen, K. M., Christensen, J. H., Brandt, J., Frohn, L. M., and Geels, C.: Modelling atmospheric transport of $\alpha$ hexachlorocyclohexane in the Northern Hemispherewith a 3-D dynamical model: DEHM-POP, Atmos. Chem. Phys., 4, 11251137, doi:10.5194/acp-4-1125-2004, 2004.

Hansen, K. M., Prevedouros, K., Sweetman, A., Jones, K. C., and Christensen, J. H.: A process-oriented inter-comparison of a box model and an atmospheric chemistry transport model: insights into model structure using $\alpha-\mathrm{HCH}$ as the modelled substance, Atmos. Environ., 40, 2089-2104, 2006.

Hansen, K. M., Christensen, J. H., Brandt, J., Frohn, L. M., Geels, C., Skjøth, C. A., and Li, Y. F.: Modeling shortterm variability of alpha-hexachlorocyclohexane in Northern Hemispheric air, J. Geophys. Res.-Atmos., 113, D02310, doi:10.1029/2007JD008492, 2008a.

Hansen, K. M., Halsall, C. J., Christensen, J. H., Brandt, J., Geels, C., Frohn, L. M., and Skjøth, C. A.: The role of the snowpack on the fate of alpha-HCH in an atmospheric chemistry-transport model, Environ. Sci. Technol., 42, 2943-2948, 2008b.

Hedegaard, G. B., Brandt, J., Christensen, J. H., Frohn, L. M., Geels, C., Hansen, K. M., and Stendel, M.: Impacts of climate change on air pollution levels in the Northern Hemisphere with special focus on Europe and the Arctic, Atmos. Chem. Phys., 8, 3337-3367, doi:10.5194/acp-8-3337-2008, 2008.

Hedegaard, G. B., Christensen, J. H., Geels, C., Gross, A., Hansen K. M., May, W., Zare, A., and Brandt, J.: Modelling the Impacts of Climate Change on Tropospheric Ozone over three Centuries, Atmos. Clim. Sci., 2, 546-561, 2012.

Hedegaard, G. B., Christensen, J. H., and Brandt, J.: The relative importance of impacts from climate change vs. emissions change on air pollution levels in the 21 st century, Atmos. Chem. Phys., 13, 3569-3585, doi:10.5194/acp-13-3569-2013, 2013.

IPCC: Climate Change 2007: Synthesis Report. Contribution of Working Groups I, II and III to the Fourth Assessment Report of the Intergovernmental Panel on Climate Change, Core Writing Team, edited by: Pachauri, R. K. and Reisinger, A., IPCC, Geneva, Switzerland, 104 pp., 2007.

Jacob, D. J. and Winner, D. A.: Effect of climate change on air quality, Atmos. Environ., 43, 51-63, 2009.

Krogseth, I. S., Kierkegaard, A., Breivik, K., McLachlan, M. S., Hansen K. M., and Schlabach, M.: Occurrence and seasonality of cyclic Volatile Methyl Siloxanes in Arctic air, Environ. Sci. Technol., 47, 502-509, 2013.

Lamon, L., von Waldow, H., MacLeod, M., Scheringer, M., Marcomini, A., and Hungerbuhler, K.: Modeling the global levels and distribution of polychlorinated biphenyls in air under a climate change scenario, Environ. Sci. Technol., 43, 5818-5824, 2009.

Langner, J., Engardt, M., Baklanov, A., Christensen, J. H., Gauss, M., Geels, C., Hedegaard, G. B., Nuterman, R., Simpson, D., Soares, J., Sofiev, M., Wind, P., and Zakey, A.: A multi-model study of impacts of climate change on surface ozone in Europe, Atmos. Chem. Phys., 12, 10423-10440, doi:10.5194/acp12-10423-2012, 2012.

Li, Y.-F., Macdonald, R. W., Jantunen, L. M. M., Harner, T., Bidleman, T. F., and Strachan, W. M. J.: The transport of $\beta$ hexachlorocyclohexane to the western Arctic Ocean: a contrast to $\alpha$-HCH, Sci. Tot. Environ., 291, 229-246, 2002.

Li, Y. F., Ren, N. Q., and Tian, C.: China-North America project on reduction of lindane usage in China and its impact globally and on North America, in: Report to North America Commission for Environmental Cooperation (CEC), Environment Canada and US EPA, Toronto, Canada, 2008.

Manders, A. M. M., van Meijgaard, E., Mues, A. C., Kranenburg, R., van Ulft, L. H., and Schaap, M.: The impact of differences in large-scale circulation output from climate models on the regional modeling of ozone and PM, Atmos. Chem. Phys., 12, 9441-9458, doi:10.5194/acp-12-9441-2012, 2012.

Marsland, S. J., Haak, H., Jungclaus, J. H., Latif, M., and Roske, F.: The Max-Planck-Institute Global Ocean/Sea Ice Model with Orthogonal Curvilinear Coordinates, Ocean Model., 5, 91-127, 2003.

McLachlan, M. S., Kierkegaard, A., Hansen, K. M., van Egmond, R., Christensen, J. H., and Skjøth, C. A.: Concentrations and Fate of Decamethylcyclopentasiloxane (D5) in the Atmosphere, Environ. Sci. Technol., 44, 5365-5370, 2010.

Nakicenovic, N., Alcamo, J., Davis, G., de Vries, B., Fenhann, J., Gaffin, S., Gregory, K., Grbler, A., Jung, T., Kram, T., Rovere, E. L., Michaelis, L., Mori, S., Morita, T., Pepper, W., Pitcher, H., Price, L., Riahi, K., Roehrl, A., Rogner, H.-H., Sankovski, A., Schlesinger, M., Shukla, P., Smith, S., Swart, R., van Rooijen, S., Victor N., and Dadi, Z.: Special Report on Emission Scenarios: A Special Report of Working Group III of the Intergovernmental Panel on Climate Change, Cambridge University Press, New York, 2000.

Roeckner, E., Bauml, G., Bonaventura, L., Brokopf, R., Esch, M., Giorgetta, M., Hagemann, S., Kirchner, I., Kornblueh, L., Manzini, E., Rhodin, A., Schlese, U., Schulzweida, U., and Tompkins, A.: The Atmospheric General Circulation Model ECHAM5, Part I, Max-Planck-Institute für Meteorologie, Hamburg, 2003.

Roeckner, E., Brokopf, R., Esch, M., Giorgetta, M., Hagemann, S., Kornblueh, E., Manzini, L., Schlese U., and Schulzweida, U.: Sensitivity of Simulated Climate to Horizontal and Vertical Resolution in the ECHAM5 Atmosphere Model, J. Climate, 19, 3771-3791, 2006.

Rogelj, J., Meinshausen, M., and Knutti, R.: Global warming under old and new scenarios using IPCC climate sensitivity range estimates, Nature Clim. Change, 2, 248-253, 2012.

Schenker, U., MacLeod, M., Scheringer, M., and Hungerbuhler, K.: Improving data quality for environmental fate models: A leastsquares adjustment procedure for harmonizing physicochemical properties of organic compounds, Environ. Sci. Technol., 39, 8434-8441, 2005

Simpson, D., Andersson, C., Christensen, J. H., Engardt, M., Geels, C., Nyiri, A., Posch, M., Soares, J., Sofiev, M., Wind, P., and Langner, J.: Impacts of climate and emission changes on nitrogen deposition in Europe: a multi-model study, Atmos. Chem. Phys., 14, 6995-7017, doi:10.5194/acp-14-6995-2014, 2014.

Skov, H., Christensen, J. H., Goodsite, M. E., Heidam, N. Z., Jensen, B. P., Wåhlin, B., and Geernaert, G.: Fate of elemental mercury in the Arctic during atmospheric mercury depletion episodes and the load of atmospheric mercury to the Arctic, Environ. Sci. Technol., 38, 2373-2382, 2004.

UNEP/AMAP: Climate Change and POPs: Predicting the Impacts, Report of the UNEP/AMAP Expert Group; Secretariat of the Stockholm Convention: Geneva, available at: http://chm.pops. int/tabid/1580/language/en-US/Default.aspx, 2011. 
Wöhrnschimmel, H., MacLeod, M., and Hungerbuhler, K.: Emissions, fate and transport of persistent organic pollutants to the Arctic in a changing global climate, Environ. Sci. Technol., 47, 2323-2330, 2013.
Xiao, H., Li, N. Q., and Wania, F.: Compilation, evaluation, and selection of physical-chemical property data for $\alpha-, \beta$-, and $\gamma$ hexachlorocyclohexane, J. Chem. Eng. Data, 49, 173-185, 2004. 